\title{
Spinal Aneurysmal Bone Cysts: Surgical Options and Clinical Outcome
}

\author{
MOHAMED R. NAGY, M.D. and MOHAMED R. RADY, M.D. \\ The Department of Neurosurgery, Faculty of Medicine, Cairo University
}

\begin{abstract}
Background: Aneurysmal bone cyst (ABC) of the spine is a rare entity. Treatment of these lesions is challenging. There are many surgical and nonsurgical options for management of spinal ABCs.

Aim of Study: The aim of this study was to describe the surgical options and the clinical outcome of aneurysmal bone cysts of the spine.

Patients and Methods: This is a retrospective study done on six patients with primary spinal ABCs. A modified Frankel scale was used for assessment of the neurological status of the patients preoperatively and during the follow-up period. The WBB (Weinstein-Boriani-Biagini) system was used to describe the extent of the lesion depending on the data collected from magnetic resonance imaging (MRI) and computed tomography (CT) scans.

Results: The mean age was $20.3 \pm 5.9$ (range, $15-30$ ) years There were four females (66.7\%) and two males (33.3\%). All the patients were stage ABCD according WBB surgical staging system. The surgical excision was complete in four patients (66.7\%) and partial in two patients (33.3\%). Out of the four patients who presented with neurological deficit, two patients (50\%) improved markedly, one patient $(25 \%)$ had moderate improvement, and the last patient $(25 \%)$ was stable; three after complete excision and one after partial excision of the tumor. While no recurrences were detected in the patients who had complete excision, the two patients (100\%) who had partial excision showed local tumor recurrence.
\end{abstract}

Conclusions: Surgical decompression of spinal ABCs can lead to significant improvement of the preoperative neurological deficits. In order to decrease the recurrence rate of ABCs of the spine, the goal of surgery should be complete excision.

Key Words: Spinal - Aneurysmal bone cyst - Surgical Outcome.

\section{Introduction}

ANEURYSMAL bone cyst ( $\mathrm{ABC}$ ) is an expansile, osteolytic pseudotumoral bone lesion. It is a rare entity, representing about $1 \%$ of all primary bone

Correspondence to: Dr. Mohamed R. Nagy, E-Mail: dr mohamedragab@hotmail.com tumors [1]. It frequently appears before the age of twenty years. It occurs slightly more frequently in females [2]. It usually involves the metaphysis of the long bones, however these tumors arise from the spine in about $10 \%$ to $30 \%$ of cases, representing about $15 \%$ of all primary spine tumors $[3,4]$ The most common presentation of these tumors is localized pain to the site of the lesion.

Treatment of spinal ABCs is challenging. Therapeutic options include surgical resection, either intralesional curettage or complete excision; arterial embolization; sclerotherapy; and radiation $[\mathbf{5 , 6}]$ The best option for local tumor control with excellent prognosis is complete excision. However, it may be complicated by vertebral instability that needs spinal stabilization $[7,8]$. The recurrence rate after partial excision is about $25 \%$, usually within the first two years after surgery [9]. Embolization has been used preoperatively to minimize the risk of bleeding during excision $[\mathbf{5 , 1 0 ]} . \mathrm{s}$

The aim of this study was to describe the surgical options and the clinical outcome of aneurysmal bone cysts of the spine.

\section{Patients and Methods}

This is a retrospective study done on six patients with spinal ABCs with histologically confirmed diagnosis who were operated upon in Neurosurgery Department, Faculty of Medicine, Cairo University in the period from March 2014 to March 2020. Exclusion criteria included $\mathrm{ABC}$ associated with other bony lesions. All the patients were classified as primary $\mathrm{ABC}$.

All patients underwent history taking, complete neurological examination. A modified Frankel scale was used for assessment of the neurological status of the patients preoperatively and during the follow-up period. The radiological assessment 
included plain antero-posterior, lateral, oblique and lateral flexion-extension X-rays views of the involved spine, computed tomography (CT) scan, and magnetic resonance imaging (MRI) of the spine. The WBB (Weinstein-Boriani-Biagini) system [11] was used to describe the extent of the lesion depending on the data collected from MRI and CT scans (Fig. 1).

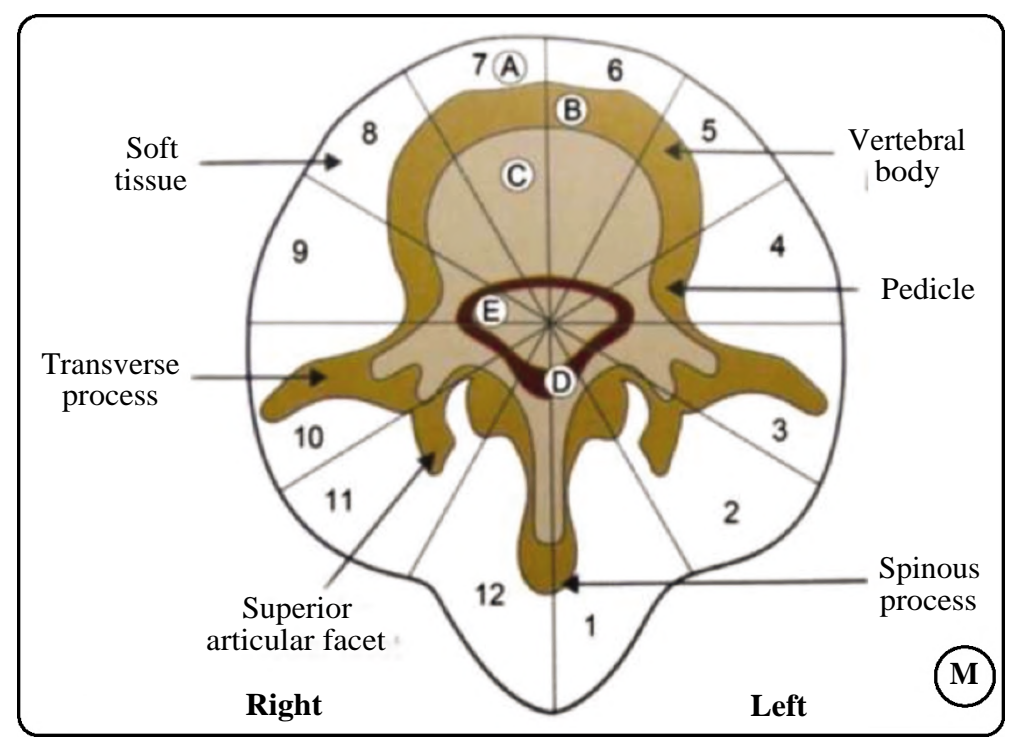

Fig. (1): Weinstein, Boriani, Biagini (WBB) staging system. It describes the transverse extension of the spinal tumors as follows: Zone 1 represents left spinous process and lamina, through zone 6 which represents left anterior wedge of vertebral body, and back to zone 12 which represents right spinous process and lamina. It also divides the vertical extension of these lesions into five concentric layers (A-E): As layer A represents extraosseous paraspinal tissues, through to layer D (extradural), and layer E (intradural) [11]

All patients underwent arterial embolization with polyvinyl alcohol particles 24 to 48 hours before surgical intervention. Diagnostic biopsy was done to confirm the diagnosis in suspicious cases and exclude other underlying lesions. The posterior approach was used in all patients as the lesion involved mainly the posterior parts of the spine. It involved exposure of the tumor through a posterior midline incision, tumor resection, decompression of the spinal cord and/or the nerve roots, and instrumentation when necessary. The tumor appears grossly multilobulated, with outer eggshell rim of bone that was continuous with the adjacent bone. The core of the tumor consisted of cystic cavities containing unclotted blood and fleshy tissues. When excising the mass leaving at least one facet joint intact, no spinal fixation was done. The anterior approach was used when there was marked involvement of the vertebral body and it was used in the cervical spine. The patient was made supine after finishing the posterior approach and the remaining part of the tumor was exposed through standard anterior cervical approach. After tumor resection, anterior spinal stabilization and fusion was done with an anterior cervical plate and cage packed with bone graft from the iliac crest.

The complete excision included removing the cyst walls and careful drilling of the bony margins of the resection cavity. The bleeding came from the soft tissues lining the blood-filled cysts and it was controlled only after all the lining had been removed. The partial excision was done through a piecemeal excision of the tumor when there was relative inaccessibility of the lesion or massive bleeding during surgery. Histopathological diagnosis was done in all patients.

During the follow-up period, the patients were assessed clinically and radiologically. Soft cervical collar or spinal orthosis were used for 3 months following surgery. The patients were shifted to the physiotherapy department for neurologic rehabilitation programs. The MRI and X-rays of the spine were scheduled postoperatively at 3 months, 6 months, and annually to detect tumor progression and to evaluate the stability of the spine.

\section{Results}

This study included six patients, four females $(66.7 \%)$ and two males $(33.3 \%)$. The mean age was $20.3 \pm 5.9$ (range, 15-30) years. As regarding the level of the lesion, there were two cervical $(33.3 \%)$, one cervicodorsal $(16.7 \%)$, two dorsal $(33.3 \%)$ lesions, and one lumbar lesion $(16.7 \%)$. The tumor extended longitudinally in one cervicodorsal and one dorsal $\mathrm{ABC}$; but the intervertebral 
disc was intact in both patients. The tumor was located in the midline in three patients $(50 \%)$, on the right side in one patient $(16.7 \%)$, and on the left side in two patients $(33.3 \%)$.

Five patients $(83.3 \%)$ presented with axial pain, three patients $(50 \%)$ with radicular pain, three patients $(50 \%)$ with motor weakness due to cord compression, and one patient $(16.7 \%)$ presented with motor weakness due to root compression (Table 1). A palpable mass was detected in two patients $(33.3 \%)$. The mean duration of symptoms was $8.5 \pm 5.6$ months (range from 1 month to 1.5 years).

Table (1): Summary of data of the study patients.

\begin{tabular}{|c|c|c|c|c|c|c|c|c|c|}
\hline No & $\begin{array}{l}\text { Age } \\
\text { (years) }\end{array}$ & Sex & Level & Symptoms & $\begin{array}{l}\text { Preop } \\
\text { Modified } \\
\text { Frankel }\end{array}$ & WBB stage & Surgery & $\begin{array}{c}\text { Final } \\
\text { Modified } \\
\text { Frankel }\end{array}$ & Recurrence \\
\hline 1 & 17 & $\mathrm{~F}$ & C6 & Neck pain, Quadriparesis & $\mathrm{Cb}$ & 10-3 ABCD & Total excision & $\mathrm{E}$ & No \\
\hline 2 & 19 & $\mathrm{~F}$ & $\mathrm{C} 7$ & $\begin{array}{l}\text { Neck pain, Right brachialgia, } \\
\text { right arm weakness }\end{array}$ & $\mathrm{D} 3 \mathrm{c}$ & 6-12 ABCD & $\begin{array}{l}\text { Total excision, } \\
\text { C6-D1 posterior } \\
\text { fixation, } \\
\text { C7 corpectomy, } \\
\text { C6-D1 cage and } \\
\text { graft, anterior plate }\end{array}$ & D3c & No \\
\hline 3 & 15 & $\mathrm{~F}$ & C7-D 1 & Neck pain, brachialgia & $\mathrm{E}$ & 10-3 ABCD & $\begin{array}{l}\text { Total excision, } \\
\text { C5,6-D2,3 pedicle } \\
\text { screws fixation }\end{array}$ & $\mathrm{E}$ & No \\
\hline 4 & 16 & M & D7- D8 & Back pain, Severe paraparesis & $\mathrm{D} 3 \mathrm{~b}$ & $12-4 \mathrm{ABCD}$ & Partial excision & $\mathrm{E}$ & Yes \\
\hline 5 & 25 & $\mathrm{~F}$ & D8 & Paraplegia & A & 9-4 ABCD & $\begin{array}{l}\text { Total excision, } \\
\text { D6-D } 10 \text { fixation }\end{array}$ & D3b & No \\
\hline 6 & 30 & M & $\mathrm{L} 2$ & Low back pain, sciatica & E & $12-5 \mathrm{ABCD}$ & Partial excision & $\mathrm{E}$ & Yes \\
\hline
\end{tabular}

As regarding the radiological evaluation of the patients with MRI or CT scan of the spine, the lesion involved the posterior elements (one or more of zones 10 to 3 ) in all patients and extended to the vertebral body in four patients (66.7\%). All the patients were stage ABCD according to WBB staging system (Table 1). Five patients $(83.3 \%)$ had spinal canal compression of varying degrees. The fluid- fluid levels were present in four patients $(66.7 \%)$. Three patients $(50 \%)$ had moderate vascularity while it was prominent in two patients $(33.3 \%)$, with no signs of vascularization in the remaining patient $(16.7 \%)$. Two patients $(33.3 \%)$ had bone edema.

All patients underwent arterial embolization before surgery without complications. Diagnostic biopsy was needed in two patients (33.3\%). Surgical excision was done for all patients. The excision was complete in four patients (66.7\%) (Fig. 2) and partial in two patients $(33.3 \%)$. The surgical approach was posterior alone in five patients $(83.3 \%)$ while the remaining patient $(16.7 \%)$ had a combined anterior-posterior approach in the same session. Spinal instrumentation was used in three patients $(50 \%)$. Surgical complications included one patient $(16.7 \%)$ with wound infection who was managed with wound debridement and proper antibiotics and two patients $(33.3 \%)$ who had significant intraopertaive bleeding that necessitate blood transfusion.

The mean follow-up period was $37.3 \pm 24.5$ months (range, 1-7 years). Out of the four patients who presented with neurological deficit, two patients $(50 \%)$ improved markedly, one patient $(25 \%)$ had moderate improvement, and the last patient (25\%) remained stable during the follow-up period according to modified Frankel scale; three after complete excision and one after partial excision of the tumor (Table 1). No recurrences were detected in the patients who had complete excision. The two patients $(100 \%)$ who had partial excision showed local tumor recurrence documented by MRI of the spine during the follow-up period. The posterior approach alone was used for lesions involving the vertebral body in these two patients. The time interval from the surgical intervention to recurrence was two months in one patient and five months in the other patient. The overall local recurrence rate was $33.3 \%$. Repeated surgery was done for one patient with recurrence while the other one received radiotherapy due to inaccessibility of the recurrent lesion. Both patients did not show any further local recurrence at their latest evaluation. No mortalities were detected in this study. 



Fig. (2): A 17-years-old female patient presented with neck pain and quadriparesis ( $\mathrm{Cb}$ according to modified Frankel scale). $(A, B)$ MRI of the cervical spine sagittal and axial views show a large expansile osseous lesion implicating the spinous process and both lamina of C6 vertebra impressive of aneurysmal bone cyst of the posterior neural element of C6 vertebra. The lesion displays isointense signal intensity in T1 and hyperintense signal intensity with multiple fluid/fluid levels and gravitating haemosiderin in T2WIs. It is seen compressing the spinal cord against the vertebral column anteriorly, abutting the nearby spinous processes of C5 and C7 vertebrae, and indenting the paraspinal muscles posteriorly. (C,D) CT of the cervical spine sagittal and axial views show that the lesion appears isodense with fluid/fluid levels. Intraoperative photos show: (E) Exposure of the tumor before excision, $(\mathrm{F})$ The tumor during excision, and $(\mathrm{G})$ Decompression of the cervical cord after total excision of the tumor. The patient improved to modified Frankel scale grade $\mathrm{E}$ after surgery. 


\section{Discussion}

Aneurysmal bone cysts are rare locally aggressive, highly vascular lesions $[\mathbf{1 , 2 , 5 , 1 2 , 1 3 ]}$. They arise from the spine in about $10 \%$ to $30 \%$ of the patients. ABCs may be primary or secondary. The primary ABCs arise de novo, while the secondary ones have an underlying lesion such as osteosarcoma, chondroblastoma, and giant cell tumor [14]. They differ from each other on the basis of a molecular background as about two thirds of the patients with primary ABCs show USP6 or CDH11 rearrangements [15]. A periosteal or intraosseous arteriovenous fistula is formed in these lesions. The high flow erodes the bony trabeculae thus creating a multiseptated thin-shelled cavity [16].

ABCs usually occur before the age of twenty years with a slightly females' prevalence $[2,17]$ The mean age in our study was $20.3 \pm 5.9$ years with a female predominance $(66.7 \%)$ which are similar to the literature. In our study, $83.3 \%$ of the patients had affection of the cervical and dorsal spine. These results are in accordance with $\mathrm{Pa}$ pagelopoulos et al. and Vergel de Dios et al., series in which the cervical and dorsal spine were affected more than lumbar spine [2,6], but are in contrast to the results found by Boriani et al. and De Kleuver et al., who reported a predilection for the lumbar spine $[\mathbf{5 , 1 8}]$. Despite The lesion involves the adjacent vertebra in about $25 \%$ to $35 \%$ of the patients, the disc space is usually intact [16]. In this study, the tumor involved more than one vertebral segment in $33.3 \%$ of the patients; results comparable with the literature.

In our study, $83.3 \%$ of the patients presented with axial pain, $50 \%$ with radicular pain, and 50\% with motor weakness due to cord compression. The most common clinical presentations of spinal $\mathrm{ABCs}$ is localized pain to the site of the lesion, which is typically worse at night, and neurological deficits due to myelopathy or radiculopathy. ABCs can also lead to a kyphotic deformity of the spine with resultant pain and neurological compromise [19].

Diagnosis of spinal ABCs depends mainly on MRI and CT scans. The lesions exhibit ballooning of the posterior elements of the spine on plain radiographs [20]. Fluid-fluid levels are usually seen on MRI and CT scans in spinal ABCs. However, this finding is not specific for these lesions as it can be also seen in any bony lesion with areas of necrosis or hemorrhage such as giant cell tumor [21]. CT scan is also useful for planning for possible instrumented spinal fusion by determining the pedicle morphology and vertebral body shape. MRI of the spine can help to differentiate ABCs which have smooth multiseptated cavity from other neoplastic masses which show nodularity [22]. In this study, both CT and MRI were done for diagnosis, surgical staging of the lesions, and to detect spinal canal compression and the degree of vascularity of the lesions.

There are many surgical and nonsurgical options for management of spinal ABCs including surgery either by complete excision or intralesional curettage, embolization, sclerotherapy, and radiotherapy $[23,24]$. Complete excision has the highest cure rates and an excellent overall prognosis. However, it has its own complications like bleeding, pain, and the risk of spinal instability [7] Partial excision is done when the lesion is relatively inaccessible or in a structurally significant region. The recurrence rate after partial excision is about $25 \%$ and is usually seen within the first 2 years after surgery $[2,5,9]$. In this study, no local recurrences were detected in four patients who underwent total excision while the two patients who had partial excision developed recurrence of the tumor two and five months postoperatively. These results are close to the results reported in the literature. Ozaki et al., reported complete excision in nine patients who had no local recurrence, whereas there were local recurrences after curettage alone done in two patients [25]. Zenonos et al., reported two recurrences after partial resection of ABCs. They occurred 9 months to 8 years after surgery [8]. Zileli et al., detected four recurrences in five patients who underwent subtotal excision, and only one recurrence in thirteen patients who had total excision [19].

Postoperative complications in this series included one patient who developed wound infection and two patients who had significant intraopertaive bleeding that necessitate blood transfusion. Boriani et al., reported in their series five patients who developed surgical wound slough; four of them after radiotherapy; requiring surgical repair and one patient who developed postoperative transient urethral compression [5]

Early diagnosis and appropriate surgical treatment are the key factors for successful management of spinal ABCs [26]. The posterior approach alone was used in five patients in this study and an anterior-posterior approach was done in the last patient. The posterior approach alone is insufficient if the vertebral bodies are affected extensively [18] Anterior approach should be used in these patients 
either in the same session or as a subsequent procedure [6]. Two patients, in our study, developed local recurrence during the follow-up period. They underwent the posterior approach alone for lesions involving the vertebral body. De Kleuver et al., reported that the recurrence rate was higher after posterior approaches ( 5 of 18 patients) than after anterior approaches (1 of 11 patients) [18]. Spinal instrumentation was used in $50 \%$ of our patients to prevent spinal instability and deformity. Spinal instability can result from extensive bony involvement by the lesion or from extensive tumor resection causing iatrogenic instability $[\mathbf{6 , 9 , 2 5 ]}$.

As regarding the clinical outcome, out of the four patients who presented in this series with neurological deficit, two patients improved markedly, one patient had moderate improvement, and the last one remained stable during the follow-up period; three after complete excision and one after partial excision of the tumor. Boriani et al., reported in their series improvement of the four patients with severe neurological deficits on presentation after surgery; one after en bloc excision and three had curettage followed by radiotherapy. They reported partial recovery in their patient who presented with complete paraplegia after surgery (from Frankel grade A to D3) [5] . Raftopoulos et al., performed a two-step surgical intervention for a 3 years old girl presented with sudden complete paraplegia due to an $\mathrm{ABC}$ of the fourth thoracic spine, resulting in complete neurological recovery and no recurrence within 2.5 years follow-up period [27].

Embolization can be performed before surgical excision to decrease the intraoperative bleeding [7]. The recurrence rate after embolization are comparable to those following surgery, and the procedure can be directed to technically difficult sites $[\mathbf{5 , 6 , 1 0 ]}$. Embolization may be considered as a primary treatment for recurrent lesions after multiple surgeries or inoperable lesions without any neurological deficit, pathological fracture or spinal instability [5]. Embolization is less invasive, repeatable, and less costly alternative option to standard surgical treatment. However, the main limitations of this modality of treatment are the proximity to vessels supplying vital structures or the absence of feeding vessels [28]. All patients in this study underwent embolization preoperatively without complications.

In this study, one patient received radiotherapy due to inaccessibility of the recurrent lesion. Radiotherapy has been usually used as an adjuvant therapy after incomplete excision of $\mathrm{ABCs}$, for recurrent lesions, inoperable lesions, and for high surgical risk patients [9]. Its complications include the risk of myelopathy, secondary malignancies, gonadal damage and axial spinal deformities due to vertebral body collapse $[\mathbf{2 , 6 , 2 3 , 2 9 ]}$. Papagelopoulos et al., reported one patient who developed postradiation osteosarcoma after 7 years leading to death [6].

\section{Conclusion:}

Surgical decompression of spinal ABCs can lead to significant improvement of the preoperative neurological deficits. In order to decrease the recurrence rate of $\mathrm{ABCs}$ of the spine, the goal of surgery should be complete excision. Complete excision has an excellent overall prognosis. Preoperative embolization can be performed to reduce the intraoperative bleeding. Radiation therapy may be needed as an adjuvant therapy in certain cases.

\section{References}

1- LEITHNER A., WINDHAGER R., LANG S., HAAS O., KAINBERGER F. and KOTZ R.: Aneurysmal bone cyst. A population based epidemiologic study and literature review. Clin. Orthop. Relat. Res., 363: 176-179, 1999.

2- VERGEL De DIOS A.M., BOND J.R., SHIVES T.C., McLEOD R.A. and UNNI K.K.: Aneurysmal bone cyst. A clinicopathologic study of 238 cases. Cancer, 69: 29212931, 1992.

3- HUVOS A.G.: Aneurysmal bone cyst. In: Bone tumors. Philadelphia, PA: W.B. Saunders Company, 726-743, 1991.

4- KRICUN M.E.: Tumors of the spine. In: Imaging of bone tumors. Philadelphia, PA: W.B. Saunders Company, 256303, 1993.

5- BORIANI S., De IURE F., CAMPANACCI L., GASBARRINI A., BANDIERA S., BIAGINI R., BERTONI F. and PICCI P.: Aneurysmal bone cyst of the mobile spine: Report on 41 cases. Spine, 26: 27-35, 2001.

6- PAPAGELOPOULOS P.J., CURRIER B.L., SHAUGHNESSY W.J., SIM F.H., EBSERSOLD M.J., BOND J.R. and UNNI K.K.: Aneurysmal bone cyst of the spine. Management and outcome. Spine, 23: 621-628, 1998.

7- SACCOMANNI R.: Aneurysmal bone cyst of spine: A review of literature. Arch. Orthop. Trauma Surg., 128: 1145-1147, 2008.

8- ZENONOS G., JAMIL O., GOVERNALE L.S., JERNIGAN S., HEDEQUIST D. and PROCTOR M.R.: Surgical treatment for primary spinal aneurysmal bone cysts: Experience from Children's Hospital Boston. J. Neurosurg Pediatr., 9: 305-315, 2012.

9- HARROP J.S., SCHMIDT M.H., BORIANI S. and SHAFFREY C.I.: Aggressive "benign" primary spine neoplasms: Osteoblastoma, aneurysmal bone cyst, and giant cell tumor. Spine, 34: S39-S47, 2009.

10- ROSSI G., RIMONDI E., BARTALENA T., GERARDI A., ALBERGHINI M., STAALS E.L., ERRANI C., BI- 
ANCHI G., TOSCANA A., MERCURI M. and VANEL D.: Selective arterial embolization of 36 aneurysmal bone cysts of the skeleton with N-2-butyl cyanoacrylate. Skelet Radiol., 39: 161-167, 2010.

11- BORIANI S., WEINSTEIN J.N. and BIAGINI R.: Spine update: Primary bone tumors of the spine. Terminology and surgical staging. Spine, 22: 1036-1044, 1997.

12- BOUBBOU M., ATARRAF K., CHATER L., AFIFI A. and TIZNITI S.: Aneurysmal bone cyst primary-about eight pediatric cases: Radiological aspects and review of the literature. Pan. Afr. Med. J., 15: 111, 2013.

13- MANKIN H.J., HORNICEK F.J., ORTIZ-CRUZ E., VILLAFUERTE J. and GEBHARDT M.C.: Aneurysmal bone cyst: A review of 150 patients. J. Clin. Oncol., 23: 6756-62, 2005.

14- MARTINEZ V. and SISSONS H.A.: Aneurysmal bone cyst: A review of 123 cases including primary lesions and those secondary to other bone pathology. Cancer, 61: 2291-2304, 1988

15- WHO OMS. WHO Classification of Tumours of Soft Tissue and Bone. 4th ed. Available at:http://apps.who.int/ bookorders/anglais/detart1.jsp?codl an- 1\&codcol70\&codcch-4005. Accessed December 13, 2018.

16- FRASSANITO P., D'ONOFRIO G.F., PENNISI G., MASSIMI L., TAMBURRINI G., MUTO M. and CALDARELLI M.: Multimodal Management of Aggressive Recurrent Aneurysmal Bone Cyst of Spine: Case Report and Review of Literature. World Neurosurgery, 126: 423-427, 2019.

17-PENNEKAMP W., PETERS S., SCHINKEL C., KUHNEN C., NICOLAS V., MUHR G. and FRANGEN T.M.: Aneurysmal bone cyst of the cervical spine. Eur. Radiol., 18: 2356-2360, 2008.

18- De KLEUVER M., Van der HEUL R.O. and VERAART B.E.E.M.J.: Aneurysmal bone cyst of the spine: 31 cases and the importance of the surgical approach. J. Pediatr. Orthop. B., 7: 286-292, 1998.

19- ZILELI M., ISIK H.S., OGUT F.E., IS M., CAGLI S. and CALLI C.: Aneurysmal bone cysts of the spine. Eur. Spine J., 22: 593-601, 2013.
20- TONOMURA E.T., RAMOS P., HEMAIS P.M., MAR CHIORI E. and GASPARETTO E.L.: Aneurysmal bone cyst at C2. Imaging evaluation after intralesional injection of calcitonin and methylprednisolone. Arq Neuropsiquiatr., 66 (3-B): 711-715, 2008.

21- DiCAPRIO M.R., MURPHY M.J. and CAMP R.L.: Aneurysmal bone cyst of the spine with familial incidence. Spine, 25 (12): 1589-1592, 2000

22- CHAN M.S., WONG Y.C., YUEN M.K. and LAM D.: Spinal aneurysmal bone cyst causing acute cord compression without vertebral collapse: CT and MRI findings. Pediatr. Radiol., 32: 601-604, 2002.

23- TSAI J.C., DALINKA M.K., FALLON M.D., ZLATKIN M.B. and KRESSEL H.Y.: Fluid-fluid level: A nonspecific finding in tumors of bone and soft tissue. Radiology, 175 (3): 779-782, 1990.

24- WEINSTEIN J.N.: Differential diagnosis and surgica treatment of primary benign and malignant neoplasm. In: Frymoyer J.W. (ed) The adult spine: Principles and practice. Raven Press, New York, 830-850, 1991.

25- OZAKI T., HALM H., HILLMANN A., BLASIUS S. and WINKELMANN W.: Aneurysmal bone cysts of the spine. Arch. Orthop. Trauma Surg., 119: 159-62, 1999.

26- GARG S., MEHTA S. and DORMANS J.P.: Modern surgical treatment of primary aneurysmal bone cyst of the spine in children and adolescents. J. Pediatr. Orthop., 25 (3): 387-392, 2005

27- RAFTOPOULOS C., HURREL A., TICKET L., SZLIWOWSKI H.B. and BROTCHI J.: Total recuperation in a case of sudden total paraplegia due to aneurysmal bone cyst of the thoracic spine. Childs Nerv. Syst., 10: 464-7, 1994

28- TSAGOZIS P. and BROSJÖ O.: Current strategies for the treatment of aneurysmal bone cysts. Orthop. Rev., 7 : 6182,2015

29- FEIGENBERG S.J., MARCUS R.B., ZLOTECKI R.A., SCARBOROUGH M.T., BERREY B.H. and ENNEKING W.F.: Megavoltage radiotherapy for aneurysmal bone cysts. Int. J. Radiat. Oncol. Biol. Phys., 49: 1243-1247, 2001. 


\section{كيس عظم تمدد الأوعية الدموية فى العمود الفقرى : الخيارات الجراحية الاوية والنتائج السريرية العهود}

كيس عظم تمدد الأوعية الدموية فى العمود الفقرى هو كيان نادر. يعتبر علاج هذه الحالات أمراً صعباً. هنائ العديد من الخيارات الجراحية وغير الجراحية لعلاج هذه الحالات.





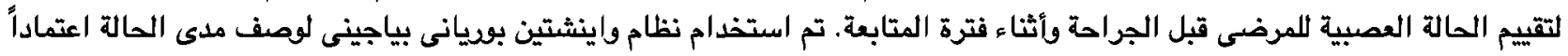



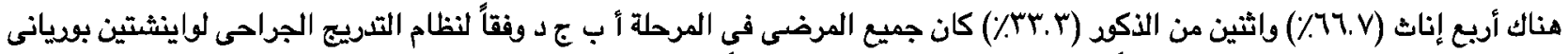



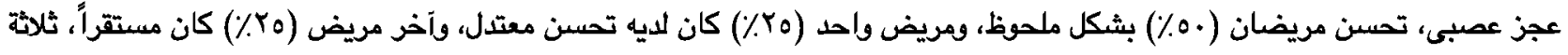

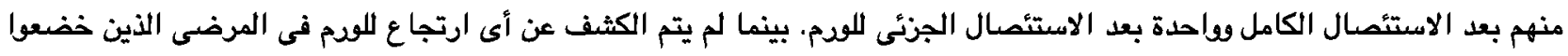

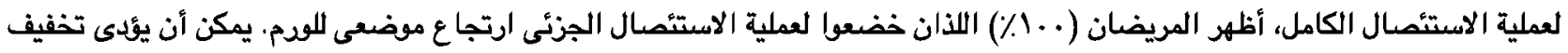



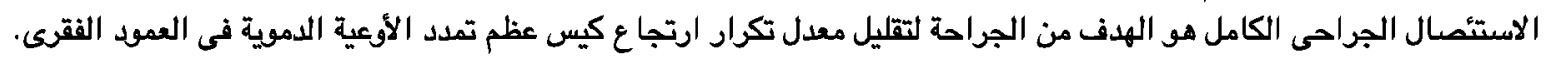

